\title{
Uso de Agentes de Interface no Ambiente TelEduc
}

\author{
Joice Lee Otsuka* \\ Ricardo Luís Lachi** \\ José Cláudio Vahl Junior ${ }^{* * *}$ \\ Heloísa Vieira da Rocha ${ }^{* * * *}$
}

\begin{abstract}
Resumo
Este artigo apresenta as duas principais linhas de pesquisas utilizando a tecnologia de agentes de interface desenvolvidas pelo grupo TelEduc. Na primeira, é focada a construção de interfaces que facilitem e promovam a colaboração entre os participantes nos cursos a distância e, na segunda, o suporte ao processo de avaliação formativa, de acordo com os interesses dos formadores.
\end{abstract}

Palavras-chave: educação a distância, agentes, avaliação formativa, coordenação, Batepapo.

\begin{abstract}
This paper presents the two main topics research using the interface agent technology that have been developed by the Teleduc group. The first one focus in the development of interfaces that make easier and promote the student collaboration inside an e-learning environment while the second focus the formative assessment support, according to the teachers' interests.
\end{abstract}

Key words: distance education, interface agents, formative assessment, coordination, chat.

\section{Introdução}

O TelEduc é um ambiente de suporte à EaD na Web que vem sendo desenvolvido desde 1997 pelo Núcleo de Informática aplicada à Educação (Nied) em parceria com o Instituto de Computação (IC), ambos da Unicamp. Este ambiente tem sido desenvolvido de forma contínua e participativa, tendo todas as suas ferramentas idealizadas, projetadas e depuradas segundo as necessidades relatadas por seus usuários [Rocha 2000].

Dessa forma, as pesquisas atuais do projeto TelEduc são resultantes de análises do uso do ambiente em situações reais de curso e têm se concentrado em duas linhas principais: o suporte à colaboração, onde estão sendo realizadas pesquisas sobre interfaces que facilitem e promovam a colaboração dentro de ambientes de $\mathrm{EaD}$, e o suporte à avaliação formativa, onde espera-se prover recursos que auxiliem o formador no acompanhamento e orientação dos processos de aprendizagem que ocorrem ao longo de um curso a distância.

Dentro destas duas linhas de pesquisa estão sendo desenvolvidos três projetos que empregam agentes de interface. Segundo Pattie Maes [1994], agentes de interface são como assistentes pessoais que colaboram com o usuário no mesmo ambiente de

\footnotetext{
${ }^{*}$ Mestre em Ciência da Computação (II/UFRGS)/ Doutoranda (IC Unicamp)/e-mail: joice@ic.unicamp.br

** Mestre em Ciência da Computação (IC/Unicamp)/ Doutorando (IC Unicamp)/e-mail: rlachi@ic.unicamp.br

**** Bacharel em Ciência da Computação (UFPel)/ Mestrando (IC Unicamp)/e-mail:jose.junior@ic.unicamp.br

***** Doutora em Computação (Unicamp)/ Professora e pesquisadora (IC e Nied Unicamp)/heloisa@ic.unicamp.br
} 
trabalho, monitorando eventos e realizando tarefas em conjunto com o usuário, e que são capazes de aprender os interesses, hábitos e preferências do usuário. Maes apresenta três abordagens de agentes de interfaces: agentes semi-autônomos, agentes baseados em conhecimento e agentes baseados em aprendizagem. Na primeira abordagem o usuário final programa o agente de interface (por meio de regras, formulários, técnicas de programação por exemplos etc.) [Lai e Malone 1988]. Na abordagem baseada em conhecimento o agente é projetado por um engenheiro do conhecimento, que é responsável por fornecer ao agente um amplo conhecimento sobre o domínio da aplicação e sobre o usuário (modelo do domínio e modelo do usuário) [Chin 1991]. A terceira abordagem é baseada em técnicas de aprendizagem de máquina [Mitchell 1997], sendo que o agente recebe um conhecimento preliminar sobre o contexto, e aprende o comportamento apropriado de forma gradativa, observando o comportamento do usuário e interagindo com outros agentes.

Segundo Lieberman [1997], o uso de agentes de interface tem se tornado cada vez mais atrativo devido a crescente complexidade das interfaces com o usuário e das tarefas para as quais estas interfaces são aplicadas. Para Laurel [apud Bradshaw 1997] a assistência dos agentes de interface destina-se a atender tarefas tediosas ou complexas, as quais o usuário não deseja fazer e se sinta confortável em delegar a uma entidade de software.

No contexto da EaD, os agentes de interface têm sido empregados principalmente para auxiliar o usuário no desenvolvimento de atividades que envolvam a monitoração e análise do imenso volume de informações resultante das interações dos participantes dentro do ambiente virtual. Além disso, o uso do ambiente TelEduc em cursos de diversas áreas em diferentes contextos, tem mostrado que é necessário o desenvolvimento de ferramentas que auxiliem os usuários em suas tarefas de forma flexível, ou seja, o suporte oferecido deve ser adaptável aos objetivos do usuário no contexto de cada curso. A característica de aprendizagem dos agentes de interface vem sendo explorada em busca dessa flexibilidade. Nas seções seguintes são apresentadas as direções das pesquisas envolvendo a tecnologia de agentes de interface desenvolvidas no escopo do projeto TelEduc.

\section{Agentes de Interface no Apoio à Colaboração}

Estudos mostram que quando os alunos interagem com os colegas de forma colaborativa eles se sentem mais engajados em suas atividades [Jaques e Oliveira 2000]. Daí a busca de novas ferramentas e tecnologias que sejam mais apropriadas a essa interação. A utilização do Bate-papo em cursos a distância tem revelado algumas dificuldades para a realização de muitas atividades, principalmente as atividades que envolvem discussão de algum tema específico.

A maioria dos ambientes de EaD utilizam ferramentas de Bate-papo tradicionais ${ }^{1}$ que, quando usados em situações de ensino-apredizagem, apresentam vários problemas. A representação seqüencial de mensagens propicia o aparecimento de diversos problemas relacionados à administração de discurso como, por exemplo, o controle de turno ${ }^{2}$ [Oeiras e Rocha 2000]. Vários participantes podem enviar mensagens

\footnotetext{
${ }_{1}^{1}$ Criadas para prover interações sociais sem finalidade específica, por exemplo, http://chat.terra.com.br

2 Denomina-se "turno" a tudo aquilo que o indivíduo faz e/ou diz quando está na sua vez de falar (Goffmann, 2000 apud Hilgert, 2000). É o turno que enfatiza o caráter dinâmico da conversação.
} 
simultaneamente, ocasionando o rompimento de controle de turno e resultando em tópicos paralelos. Vários tópicos paralelos causam a chamada "dispersão temática", muito presente em Bate-papos sociais. Assim, torna-se complexo acompanhar uma discussão, pois surgem diversos "fios de conversa" e é necessário que o usuário faça, mentalmente, as ligações coesivas entre os enunciados de um mesmo fio [McCleary 1996]. Especificamente em Bate-papos no contexto de educação, esse fato torna-se um agravante, pois, além da complexidade do assunto em pauta, o participante deve ainda dividir sua concentração com a ferramenta em si, quando esta deveria ser apenas um meio para comunicar sua mensagem. Usuários freqüentes de Bate-papo em ambientes de educação (especificamente o TelEduc) relatam que gostariam de terminar uma sessão de Bate-papo "menos cansados" e atribuem parte desse cansaço ao modo de funcionamento da própria ferramenta.

Na conversa presencial a possibilidade da troca de turno entre os interlocutores fica evidenciada por uma série de recursos metalinguísticos ausentes no Bate-papo por computador [Hilgert 2000]. Dessa forma, foi desenvolvida uma pesquisa envolvendo o uso de agentes para prover suporte à coordenação de sessões de Bate-papo. Com o suporte à coordenação espera-se adequar a ferramenta de Bate-papo ao contexto da $\mathrm{EaD}$.

Esta pesquisa explora a tecnologia de agentes para estabelecer diferentes formas de coordenação em uma ferramenta de Bate-papo chamada ChEd (Chat Educacional) implementada no TelEduc. Sabemos como funcionam diferentes protocolos sociais que são aplicados na comunicação face a face. O desafio está em "ensinar" um agente para atuar fazendo o controle de turno de uma sessão, seguindo critérios que variam de acordo com a modalidade de coordenação escolhida.

Para estabelecer as formas de coordenação a serem apoiadas foi realizada uma pesquisa por meio de sugestões de usuários e de uma análise da literatura [Harasim 1996]. Por meio dessa pesquisa foram delineadas algumas diretrizes para a aplicação de metáforas de esquemas geralmente adotados em ambientes presenciais, chegando-se a três formatos iniciais:

- Assembléia: na assembléia todos os participantes têm o mesmo direito para falar e devem levantar a mão para pedir a palavra. Ao levantar a mão, um participante é inserido na lista de espera pelo coordenador da assembléia que informa quando for sua vez da pessoa falar. Ao direito de resposta é dada prioridade na lista de espera, o que implica que um outro participante pode passar "na frente" na lista de espera se ele for responder a algo que foi dito;

- Seminário: o funcionamento do seminário é semelhante ao da assembléia, pois é necessário levantar a mão para pedir a palavra e o coordenador do seminário também privilegia as mensagens dos participantes que estão respondendo a mensagem de outra pessoa. A diferença entre a Assembléia e o Seminário está no fato de que existe um grupo de pessoas responsáveis pelo seminário e as mensagens desse grupo também têm maior prioridade;

- Café Virtual: é semelhante aos Bate-papos tradicionais, com exceção do fato de que a participação é restrita às pessoas que foram convidadas.

$\mathrm{Na}$ ferramenta implementada, o papel do coordenador descrito acima é desempenhado por um agente rodando no servidor que coordena a troca de mensagens. Como estas modalidades de coordenação possuem regras fixas e bem definidas, optouse pela utilização da abordagem de agentes de interface baseada em conhecimento. 
Neste caso o agente é dotado de conhecimentos sobre as regras de coordenação destes modelos pré-definidos e atua de acordo com estas.

A fim de prover maior flexibilidade, foi desenvolvida também uma modalidade de coordenação personalizada explorando a abordagem de agentes de interface semiautônomos, que são programados pelo usuário de acordo com seus interesses. Neste caso, o usuário define regras explícitas para a realização de uma determinada tarefa e as "ensina" ao agente por meio de uma interface como mostrada na Figura 1. Através dessa interface é possível também utilizar as configurações de sessões já realizadas anteriormente por outros formadores do mesmo curso.

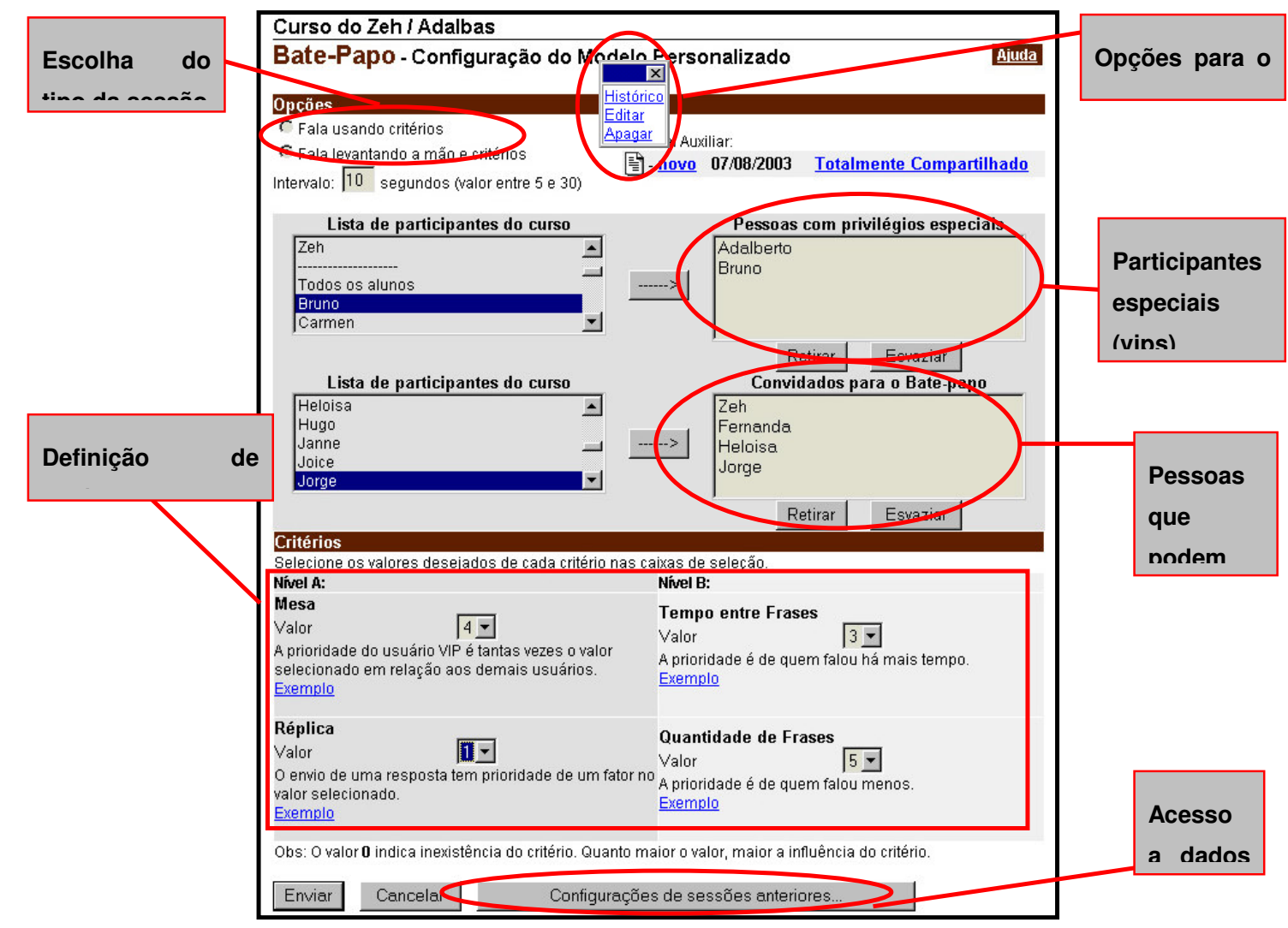

Interface de configuração do modelo personalizado 


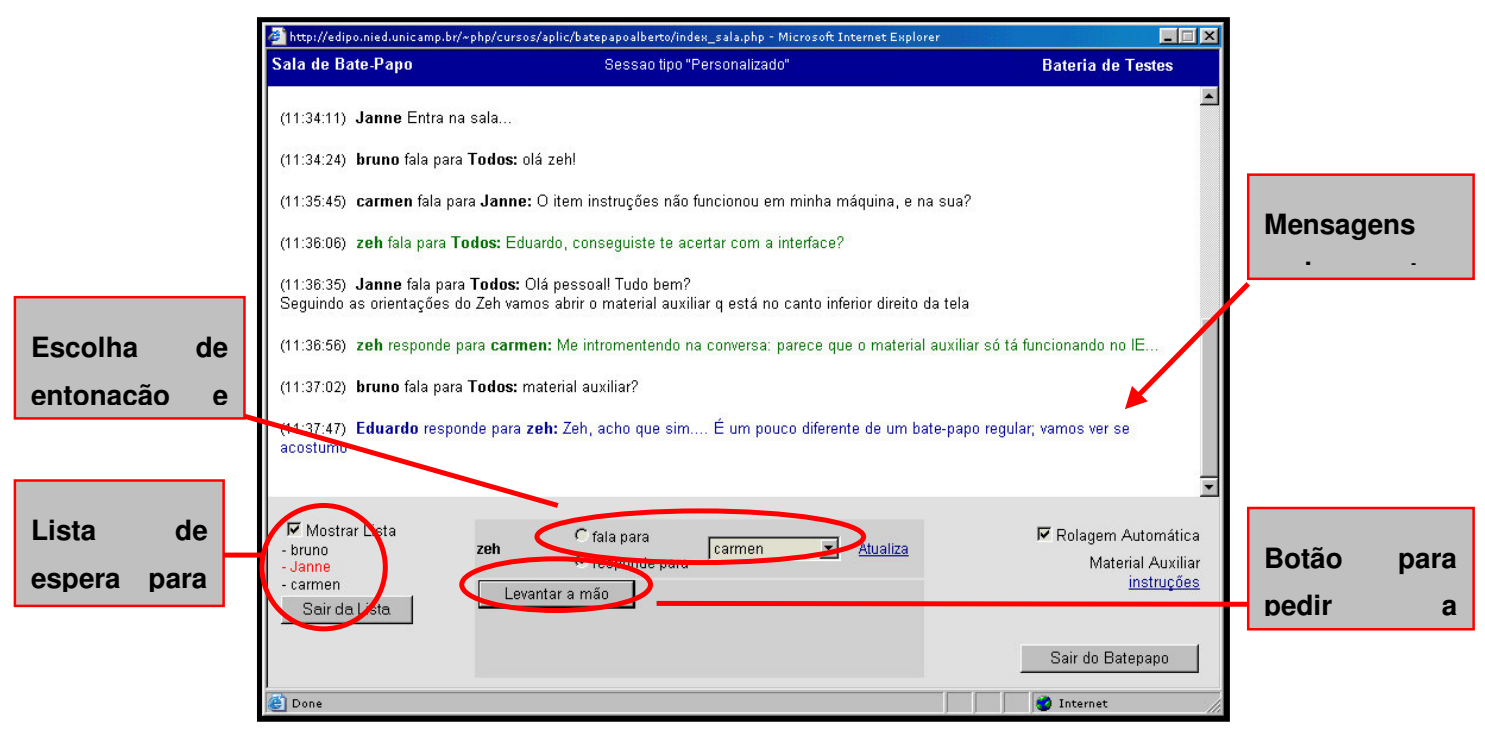

Sessão personalizada com a metáfora de levantar a mão

As sessões de bate-papo no ambiente TelEduc são previamente agendadas pelo formador (professor) do curso. No momento do agendamento o formador configura a sessão de bate-papo determinando quem serão os participantes especiais (VIPs) ${ }^{3}$, a metáfora de bate-papo a ser usada, o material auxiliar disponibilizado para aquela sessão etc. Na Figura 2 é apresentada a interface de uma sessão de bate-papo personalizada, que usa a metáfora de "levantar a mão" (como a assembléia e o seminário).

O design de novas ferramentas de bate-papo vem sendo alvo de muitas pesquisas atuais, pois tem sido constatado que, quando se quer realizar atividades síncronas para a discussão, os atuais formatos de bate-papo não são adequados. $\mathrm{O}$ uso de agentes de interface na definição de novos modelos de bate-papo busca explorar essa tecnologia para a adequação da ferramenta de Bate-papo às especificidades de diferentes cursos.

\section{Agentes de Interface no Suporte à Avaliação Formativa}

A avaliação formativa pode ser entendida como "toda prática de avaliação contínua que pretenda melhorar as aprendizagens em curso, contribuindo para o acompanhamento e orientação durante todo seu processo de formação. É formativa toda a avaliação que ajuda o aluno a aprender e a se desenvolver, que participa da regulação das aprendizagens e do desenvolvimento no sentido de um projeto educativo" [Perrenoud 1999]. A avaliação neste novo paradigma deixa de ser apenas um instrumento de verificação da aprendizagem para atuar diretamente no processo de ensino-aprendizagem, de forma contínua, durante todo o processo.

A avaliação formativa tem características informativa e reguladora [Hadji 2001], ou seja, fornece informações aos dois atores do processo de ensino-aprendizagem: ao

${ }^{3}$ VIPs são pessoas cujas mensagens possuem prioridade de publicação sobre as demais . 
professor, que será informado dos efeitos reais de suas ações, podendo regular sua ação pedagógica; e ao aprendiz, que terá oportunidade de tomar consciência de suas dificuldades e, possivelmente, reconhecer e corrigir seus próprios erros. A observação do uso dessa abordagem de avaliação em cursos oferecidos totalmente a distância por pesquisadores do Núcleo de Informática Aplicada a Educação (Nied) da Unicamp mostrou que o processo de avaliação formativa tem uma especial importância no contexto da $\mathrm{EaD}$, já que o constante acompanhamento e orientação do processo de aprendizagem, intrínsecos a esta forma de avaliação, contribuem para uma maior motivação dos aprendizes e uma melhor percepção de suas dificuldades.

No entanto, a maioria dos ambientes de EaD atuais não são apropriados para o apoio à avaliação formativa. No TelEduc a avaliação formativa é realizada por meio do acompanhamento dos registros das ferramentas de comunicação (Fórum de Discussões, Bate-Papo, Correio, Portfólio e Diário de Bordo) e auxílio dos dados gerados pelas ferramentas Acessos e InterMap. A ferramenta Acessos permite a geração de relatórios sobre os acessos dos alunos ao curso ou às ferramentas do mesmo, e a ferramenta InterMap utiliza técnicas de visualização de informações para mapear as interações realizadas, facilitando a visualização das participações dos alunos.

O processo de avaliação formativa no TelEduc ainda demanda muito trabalho e tempo do professor no acompanhamento, análise e orientação das atividades desenvolvidas ao longo do curso. Prover suporte a esta forma de avaliação é uma tarefa complexa, não sendo possível a pré-determinação dos métodos e critérios de avaliação, já que estes são ajustados ao longo do curso, de acordo com os objetivos de aprendizagem dos formadores [Otsuka e Rocha 2002].

Em busca de uma solução mais flexível, algumas pesquisas do projeto TelEduc estão sendo desenvolvidas usando agentes de interface baseados em aprendizagem. $\mathrm{Na}$ subseção 3.1 são apresentados os primeiros resultados dessa linha de pesquisa obtidos com um projeto de mestrado que teve como foco o desenvolvimento de um agente de interface para auxílio à seleção das mensagens de uma sessão de Bate-papo e na seção 3.2 são apresentadas as idéias principais de um projeto de doutorado que propõe um modelo de suporte à avaliação formativa baseado em agentes de interface.

\subsection{Suporte à análise de sessões de Bate-papo}

A fim de diminuir o volume de informações a serem analisadas pelo formador foi desenvolvido um projeto de mestrado [Lachi, 2003] aplicando agentes de interface para a seleção automática das mensagens de uma sessão de Bate-papo realizada no ambiente TelEduc, de acordo com os interesses do formador.

A ferramenta de Bate-papo atual do TelEduc sempre salva um registro com todas as mensagens de uma sessão de Bate-papo realizada no ambiente. No entanto, a interface de acesso a esse registro (Figura 3) possibilita apenas a visualização do conjunto de mensagens de uma sessão, não sendo possível a seleção de mensagens pelo usuário. 


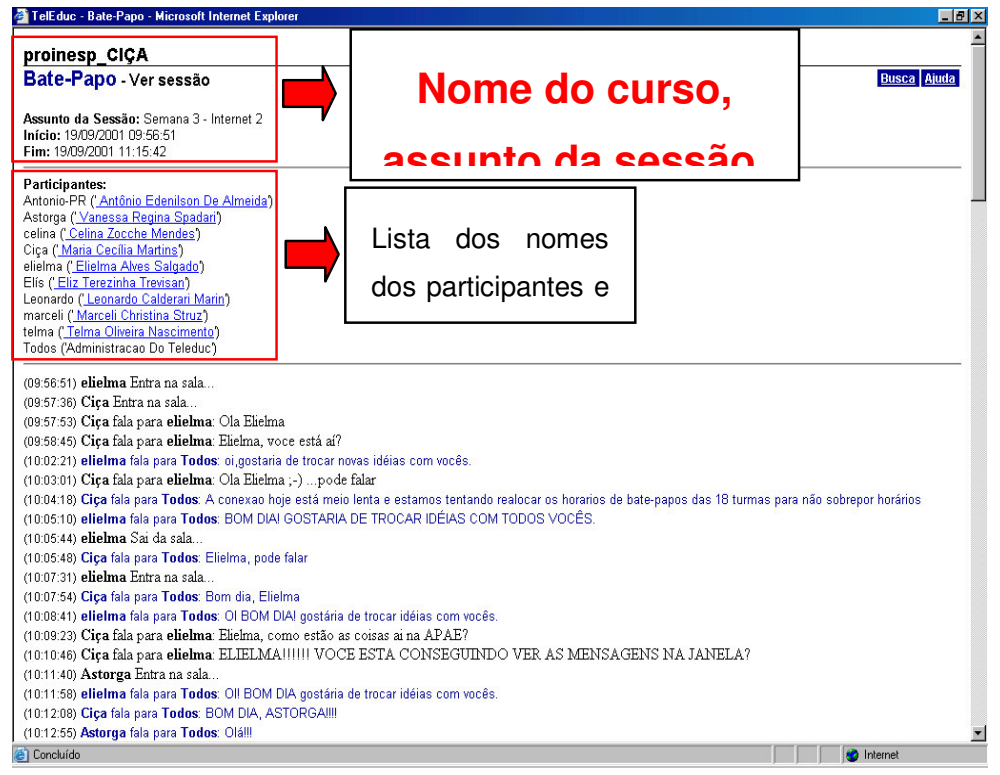

Visualização do registro de uma sessão de Bate-papo. Além das mensagens, também são apresentadas informações sobre o assunto agendado para a sessão e a listagem dos nomes dos participantes e respectivos apelidos.

Dessa forma, foi necessário um (re)design do registro das sessões, a fim de possibilitar a seleção de mensagens pelo usuário e indicação dos critérios da seleção. Nessa nova interface foi mantida a apresentação de todas as informações que já existiam na interface original e acrescentadas algumas novas, como é apresentado na Figura 4.

Ao selecionar uma mensagem o formador pode informar alguns dos critérios que o levaram a tal seleção. Os critérios passíveis de serem indicados pelo professor como sendo o motivo para a seleção de uma determinada mensagem são: o apelido da pessoa que enviou ou recebeu uma mensagem, a entonação da fala presente na mensagem, e qualquer uma das palavras presentes na mensagem (Figura 5).

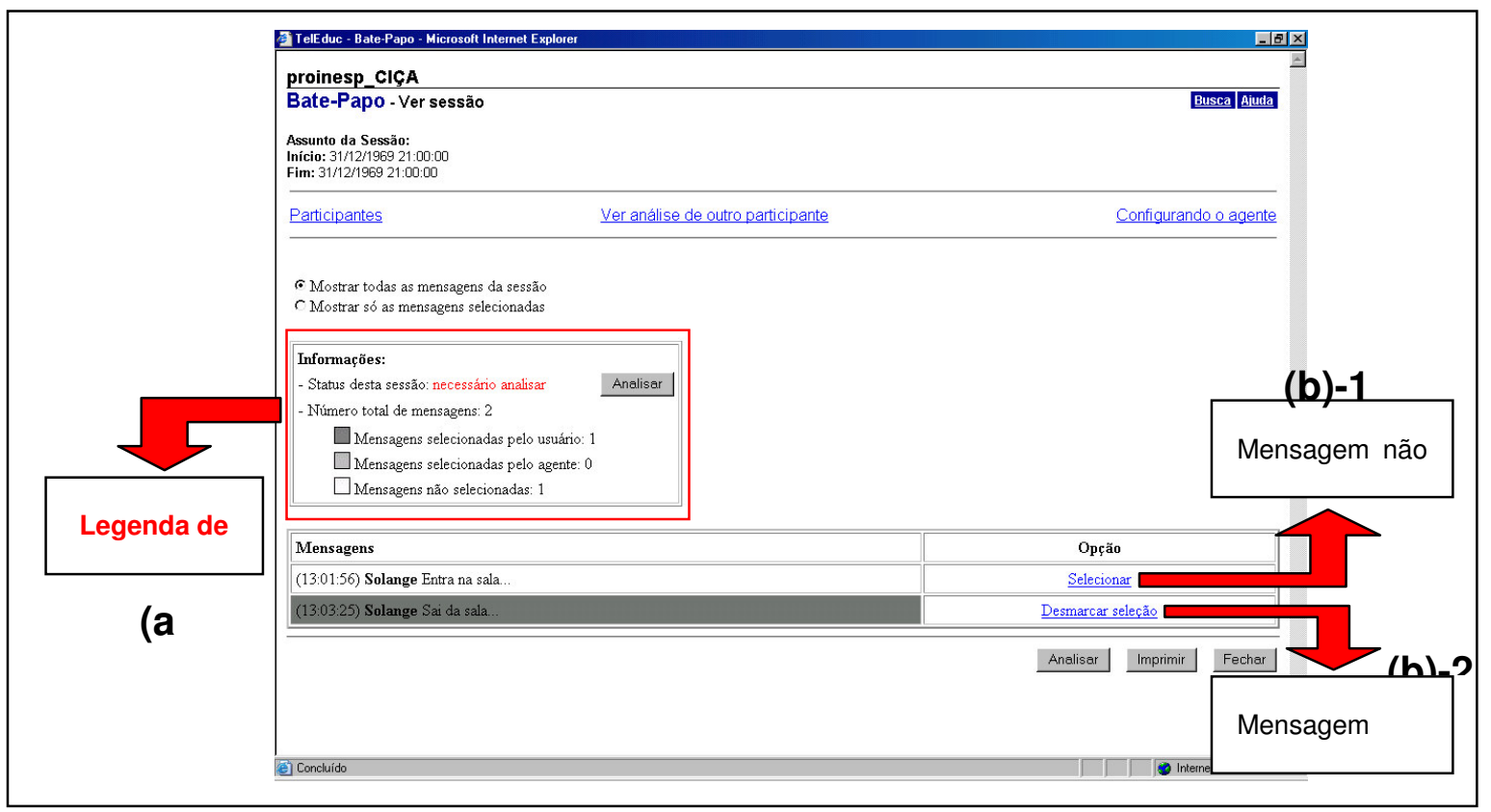


Interface de visualização das informações apresentadas pelo agente. (a) Informações do agente: “status" da sessão, número total de mensagens da sessão, número de mensagens selecionadas pelo usuário e número de mensagens selecionadas pelo agente. (b)-1 Visualização de uma mensagem não selecionada: fundo branco e a única opção disponível é a opção "Selecionar". (b)-2 Visualização de uma mensagem selecionada pelo usuário: fundo cinza escuro e a única opção disponível é a opção "Desmarcar seleção”.

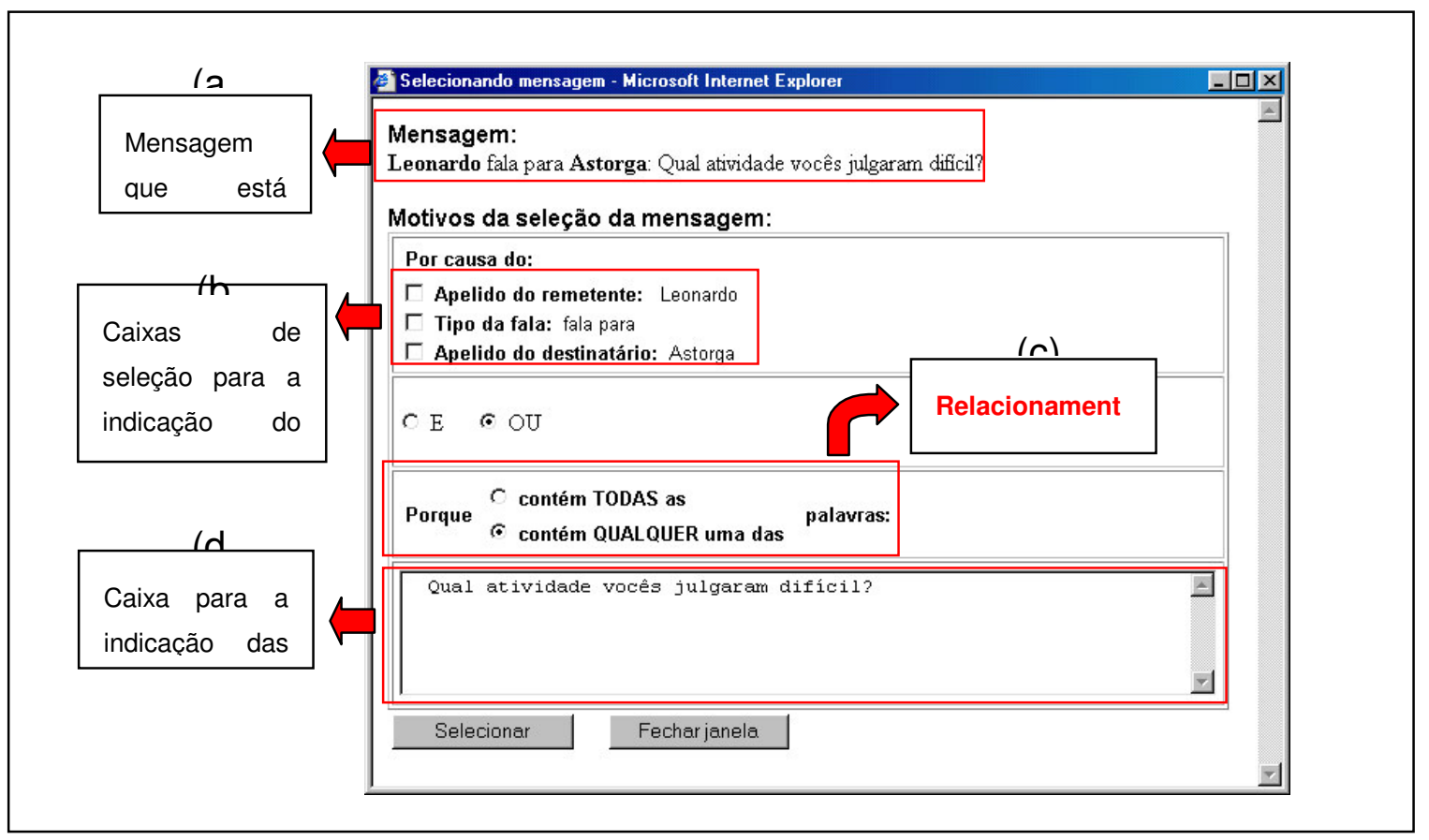

Figura 5: Janela de indicação dos critérios de seleção de uma mensagem. (a) A mensagem que o usuário está selecionando. (b) Caixas de seleção para poder indicar o remetente, entonação da fala e destinatário como motivos da seleção da mensagem. (c) Relacionamento entre as palavras-chave. (d) Caixa para indicar as palavras-chave da mensagem como motivo da seleção da mensagem. Essa caixa já aparece preenchida com o texto da mensagem no intuito de diminuir o trabalho do usuário.

Outra forma de aprendizagem do agente é por meio do feedback do professor, que ocorre quando as seleções feitas pelo agente são revisadas pelo professor (marcando mensagens não selecionadas e/ou cancelando seleções realizadas pelo agente) [Lachi, Otsuka e Rocha 2002].

A última forma pela qual o agente pode selecionar mensagens para o formador é por meio da aplicação de um algoritmo de classificação bayesiano que procura por padrões nos critérios armazenados na sua base de conhecimentos e seleciona novas mensagens com base neles [Lachi, 2003]. Essa opção pode ser habilitada ou desabilitada pelo usuário a qualquer momento.

Resultados de testes preliminares apresentaram resultados promissores do desempenho do agente na tarefa de auxiliar na seleção das mensagens de uma sessão de Bate-papo. Os usuários demonstraram uma boa aceitação do auxílio disponibilizado pelo agente, considerando-o uma ferramenta útil na seleção das mensagens relevantes de uma sessão de Bate-papo.

Além disso, nos testes surgiram diversas sugestões de pontos que devem ser considerados em futuros aprimoramentos do agente, tais como, a inclusão de caminhos mais rápidos para a seleção de mensagens (atalhos) e a disponibilização de mais informações para o usuário como, por exemplo, quais participantes de uma sessão de Bate-papo fizeram contribuições relevantes, isto é, tiveram mensagens selecionadas, dentre outras. 


\subsection{Modelo de suporte à avaliação formativa baseado em Agentes de Interface}

Este projeto está sendo desenvolvido com o intuito de propor um modelo de suporte à avaliação formativa em ambientes de EaD que auxilie o formador no processos de acompanhamento e análise de atividades ao longo do curso, adaptando-se às necessidades do formador. O modelo que vem sendo desenvolvido é baseado em uma comunidade de agentes de interface que atuarão com o objetivo atender os seguintes requisitos:

1. Auxiliar o formador no acompanhamento dos registros de interações e avaliações relacionadas às atividades propostas;

2. Auxiliar na identificação de possíveis problemas que possam comprometer os processos de aprendizagem em andamento;

3. Auxiliar o formador na avaliação de atividades a partir de critérios definidos durante o planejamento da atividade ou "aprendidos" com o formador;

4. Auxiliar na análise do desenvolvimento dos alunos em cada atividade (visão local por atividade) e em cada tópico trabalhado no curso (visão global).

O modelo inicial proposto é baseado em três tipos de agentes (modelados como classes): Agentes Monitores, Agentes Analisadores e Agentes Avaliadores. Estes serão especializados e instanciados para cada ferramenta de comunicação do ambiente, oferecendo um acompanhamento local das atividades desenvolvidas em cada ferramenta. O modelo prevê também especializações dos Agentes Analisadores e Avaliadores que atuarão observando todas as atividades desenvolvidas no curso, oferecendo uma visão global destas. A seguir são apresentados os três tipos de agentes propostos:

- Agentes Monitores: cada ferramenta de comunicação do ambiente será observada por um agente monitor, responsável por rastrear periodicamente os registros de interações e avaliações de cada atividade desenvolvida na ferramenta em questão, coletando índices quantitativos e qualitativos sobre as participações dos alunos nestas atividades;

- Agentes Analisadores: os índices coletados pelos Agentes Coletores são analisados pelos Agentes Analisadores por meio de regras que representarão um conjunto inicial de eventos que deverão ser detectados como problemas. Estas regras deverão ser ajustadas durante o curso, de acordo com o feedback do formador;

- Agentes Avaliadores: estes agentes auxiliarão o formador na análise de atividades a partir de critérios definidos durante o planejamento da atividade ou aprendidos com o formador durante o processo de avaliação (pela informação direta do formador, por meio do feedback direto do formador, ou pelo uso de métodos de aprendizagem de máquina aplicados em instâncias de treinamento obtidas a partir dos índices de participações e respectivas notas em avaliações já realizadas).

Com esse modelo espera-se explorar a facilidade de se registrar tudo o que ocorre em um curso a distância mediado por computadores, a fim de prover um suporte flexível à avaliação formativa, por meio da tecnologia de agentes de interface.

\section{Considerações Finais}


No suporte à colaboração o desafio está em proporcionar espaços adequados para a formação de grupos e favorecimento das interações colaborativas no contexto da EaD. As novas ferramentas de comunicação que têm sido pensadas nesse sentido devem ser flexíveis o suficiente para atenderem as expectativas de diferentes estilos de formadores e proporcionarem o ganho pedagógico esperado. No caso específico do suporte à coordenação de sessões de Bate-papo estão sendo adotadas duas abordagens de agentes de interface: a abordagem baseada em conhecimentos está sendo usada nas modalidades de coordenação pré-definidas que não variam para diferentes formadores; já a abordagem de agentes de interface semi-autônomos está sendo usada para possibilitar a criação de uma modalidade de coordenação de Bate-papo personalizada, de acordo com os interesses do formador.

Já na avaliação formativa, não é possível a pré-determinação de um conjunto de tipos de atividades e critérios de avaliação que atendam aos objetivos de qualquer curso, em qualquer contexto. Logo, um grande desafio no suporte a esta forma de avaliação é prover soluções adaptáveis a cada curso, de acordo com os objetivos pedagógicos dos formadores, e neste caso está sendo explorada a abordagem de agentes de interface baseada em aprendizagem. Os primeiros resultados obtidos a partir do uso desta abordagem de agentes de interface para prover suporte adaptativo à seleção de mensagens dos registros de sessões de Bate-papo foram bem promissores e são importantes indicativos da viabilidade do uso desta tecnologia para prover uma solução mais ampla de suporte à avaliação formativa baseado em agentes de interface.

\section{Referências Bibliográficas}

Bradshaw, J. M. (1997) An Introduction to software Agents. In: Bradshaw, J. M. (Ed.). Software Agents. Menlo Park, Calif.: AAAI Press, 1997.

Chin, D. Intelligent Interfaces as agents. (1991) In J. Sullivan and S. Tyler (eds). Intelligent User Interfaces. ACM Press, N.Y., 1991.

Fernández, Francisco Aguadero. (1997) La Cultura Audiovisual. Editorial Ciência. 208 p. Madri, Espanha.

Hadji, C. (2001). Avaliação Desmistificada. Porto Alegre: Artmed, 2001.

Harasim, L. (1996) Learning Networks: A Field Guide to Teaching and Learning Online. The MIT Press - Cambridge, Massachusetts - London, England.

Hilgert, José Gaston. (2000) A construção do texto "falado" por escrito: a conversação na Internet. Fala e Escrita em questão. Organizado por Dino Preti. São Paulo: Humanitas/FFLCH/USP, 2000. p. 17-55.

Jacques, P. e Oliveira F. (2000) Um Experimento com Agentes de Software para Monitorar a Colaboração em Aulas Virtuais. Workshop de Informática na Escola.

Lachi, R. L.; Otsuka, J. L.; Rocha, H. V (2002). Uso de Agentes de Interface no Suporte à Análise de Sessões de Bate-papo. In: IHC 2002 (a ser publicado).

Lachi, R. L. Chapa: Um Agente de Interface para Ferramentas de Bate-papo em Ambientes de Ensino à Distância na Web. Dissertação de Mestrado, IC-Unicamp, 2003. Disponível em: http://teleduc.nied.unicamp.br.

Lai, K.; Malone T; Yu,K. (1988) Object Lens: A spreadsheet for cooperative work. ACM 
Trans.Office Inf. Syst.

Lieberman, H. Autonomous Interface Agents. (1997) CHI 97. Atlanta. Disponível em: http://lieber.www.media.mit.edu/people/lieber/Lieberary/Letizia/AIA/AIA.html

Maes, P. (1994). Agents that Reduce Work and Information Overload. Communications of the ACM. 37 (7), julho, 1994.

McCleary, Leland E. (1996) Aspectos de uma modalidade mediada por computador. São Paulo: USP, 1996. 171p. Tese (Doutorado em Semiótica e Lingüística Geral) Faculdade de Filosofia, Letras e Ciências Humanas, Universidade de São Paulo.

Mitchell, T. (1997) Machine Learning. McGraw Hill, 1997.

Oeiras, Janne Y. Y., Rocha, Heloísa V. (2000) Uma modalidade de comunicação mediada por computador e suas várias interFACES. In: Anais do Workshop sobre Fatores Humanos em Sistemas Computacionais, 2000, Gramado-RS. Porto Alegre: Instituto de Informática da UFRGS, p. 151-160.

Otsuka, J. L.; Rocha, H. V. (2002) Avaliação Formativa em Ambientes de EaD. In: XIII Simpósio Brasileiro de Informática na Educação (SBIE 2002). São Leopoldo, 12-14 de novembro, 2002.

Perrenoud, P. (1999). Avaliação: da excelência à regulação das aprendizagens entre duas lógicas. Porto Alegre: Artes Médicas, 1999.

Rocha, H. (2002). O ambiente TelEduc para Educação à Distância baseada na Web: Princípios, Funcionalidades e Perspectivas de desenvolvi-mento. In: Moraes, M.C. (Org). Educação à Distância: Fundamentos e Práticas. Campinas, SP:Unicamp/Nied, 2002, pp. 197-212.

Vahl, J., Oeiras J. e Rocha H. (2002) Uso de agentes de interface para adequação de Batepapos ao contexto de educação a distância. IHC 2002. 